\title{
Interactive comment on "Seasonal patterns of surface inorganic carbon system variables in the Gulf of Mexico inferred from a regional high-resolution ocean-biogeochemical model" by Fabian A. Gomez et al.
}

Fabian A. Gomez et al.

fabian.gomez@pucv.cl

Received and published: 16 January 2020

Please find our responses in the Supplement link.

Please also note the supplement to this comment:

https://www.biogeosciences-discuss.net/bg-2019-430/bg-2019-430-AC2- 